Article

\title{
Pre-Pregnancy Obesity vs. Other Risk Factors in Probability Models of Preeclampsia and Gestational Hypertension
}

\author{
Małgorzata Lewandowska ${ }^{1,2, * \mathbb{C}}$, Barbara Więckowska ${ }^{3}$, Stefan Sajdak ${ }^{2}$ and Jan Lubiński ${ }^{4}$ \\ 1 Medical Faculty, Lazarski University, 02-662 Warsaw, Poland \\ 2 Division of Gynecological Surgery, University Hospital, 33 Polna Str., 60-535 Poznan, Poland; \\ ssajdak@ump.edu.pl \\ 3 Department of Computer Science and Statistics, Poznan University of Medical Sciences, \\ 60-806 Poznan, Poland; barbara.wieckowska@ump.edu.pl \\ 4 Department of Genetics and Pathology, International Hereditary Cancer Center, Pomeranian Medical \\ University, 71-252 Szczecin, Poland; lubinski@pum.edu.pl \\ * Correspondence: mal2015lewandowska@gmail.com
}

Received: 11 August 2020; Accepted: 31 August 2020; Published: 2 September 2020

\begin{abstract}
In the face of the obesity epidemic around the world, attention should be focused on the role of maternal obesity in the development of pregnancy. The purpose of this analysis was to evaluate the prediction of preeclampsia (PE) and isolated gestational hypertension $(\mathrm{GH})$ for a number of maternal factors, in order to investigate the importance of pre-pregnancy obesity (body mass index, BMI $\geq 30 \mathrm{~kg} / \mathrm{m}^{2}$ ), compared to other risk factors (e.g., prior PE, pregnancy weight gain (GWG), infertility treatment, interpregnancy interval, family history, the lack of vitamin supplementation, urogenital infection, and socioeconomic factors). In total, 912 women without chronic diseases were examined in a Polish prospective cohort of women with a single pregnancy (recruited in 2015-2016). Separate analyses were performed for the women who developed GH $(n=113)$ vs. 775 women who remained normotensive, as well as for those who developed PE $(n=24)$ vs. 775 controls. The probability of each disease was assessed for the base prediction model (age + primiparity) and for the model extended by one (test) variable, using logistic regression. Three measures were used to assess the prediction: area under curve (AUC) of the base and extended model, integrated discrimination improvement (IDI) (the index shows the difference between the value of the mean change in the predicted probability between the group of sick and healthy women when a new factor is added to the model), and net reclassification improvement (NRI) (the index focuses on the reclassification table describing the number of women in whom an upward or downward shift in the disease probability value occurred after a new factor had been added, including results for healthy and sick women). In the GH prediction, AUC increased most strongly when we added BMI $\left(\mathrm{kg} / \mathrm{m}^{2}\right)$ as a continuous variable (AUC $=0.716, p<0.001$ ) to the base model. The highest IDI index was obtained for prior GH/PE (IDI $=0.068, p<0.001$ ). The addition of BMI as a continuous variable or BMI $\geq 25 \mathrm{~kg} / \mathrm{m}^{2}$ improved the classification for healthy and sick women the most (NRI $=0.571, p<0.001)$. In the PE prediction, AUC increased most strongly when we added BMI categories (AUC $=0.726, p<0.001$ ) to the base model. The highest IDI index was obtained for prior GH/PE (IDI $=0.050, p=0.080$ ). The addition of BMI categories improved the classification for healthy and sick women the most $(\mathrm{NRI}=0.688 ; p=0.001)$. After summing up the results of three indexes, the probability of hypertension in pregnancy was most strongly improved by BMI, including BMI $\geq 25 \mathrm{~kg} / \mathrm{m}^{2}$ for the GH prediction, and BMI $\geq 30 \mathrm{~kg} / \mathrm{m}^{2}$ for the PE prediction. Main conclusions: Pre-pregnancy BMI was the most likely factor to increase the probability of developing hypertension in pregnancy, compared to other risk factors. Hierarchies of PE and GH risk factors may suggest different (or common) mechanisms of their development.
\end{abstract}


Keywords: obesity; gestational hypertension; preeclampsia; pregnancy; risk factors; prediction

\section{Introduction}

The severity of the obesity epidemic in the world is one of the reasons why we focused our attention on the assessment of the role of maternal obesity in the development of pregnancy [1,2]. Many studies have confirmed that pre-pregnancy obesity is an important part of the Development of Health and Disease $(\mathrm{DOHaD})$ concept, in which factors influencing the intrauterine environment are risk factors for non-communicable diseases in adulthood. The search for evidence linking pre-pregnancy obesity to fetal "programming" and intergenerational effects is ongoing [3-6].

Pre-pregnancy obesity has been recognized as a strong risk factor for pregnancy-induced hypertension, independent of the influence of other confounders [7-12], but this does not prejudge us against the importance of obesity compared to other maternal risk factors [7]. The hierarchy of risk factors in predicting hypertension in pregnancy has not been established, and choosing how to compare their effects can be challenging.

Pregnancy-induced hypertension (PIH) is one of the serious complications of pregnancy and includes two main forms, preeclampsia (PE) (a more severe form which is phenotypically heterogeneous and accompanied by organ dysfunction) and isolated gestational hypertension (GH) [13-15]. Pregnancy-induced hypertension occurs, on average, in $10 \%$ of the pregnant population, but, in some regions of the world, its incidence is higher [14,15]. Hypertension in pregnancy, especially preeclampsia (PE), is one of the main causes of mortality and morbidity in mothers and their babies, and the effects of the disease are not only limited to the perinatal period, but also have long-term effects related to, e.g., a future higher risk of cardiovascular disease in both mothers and babies [13,15-19]. Early identification of women at risk of PIH is needed so they can be placed under increased surveillance as early as possible.

However, despite significant advances in understanding many of the molecular processes involved in the pathogenesis of preeclampsia, a reliable method of predicting hypertension in pregnancy remains yet to be developed. Maternal risk factors are still an important element in risk identification $[13,15,20]$. In many studies, a higher risk of preeclampsia (PE) and/or GH has been associated with pre-pregnancy obesity (body mass index, $\mathrm{BMI} \geq 30 \mathrm{~kg} / \mathrm{m}^{2}$ ), comorbidities (such as chronic hypertension), older maternal age, primiparity, diagnosis of PE in a previous pregnancy, as well as with PE in the mother or a sister, and short or long gaps between pregnancies. Other factors include assisted reproductive techniques, race, and ethnicity (higher risk can be observed in Afro-Caribbean and South Asian women), as well as excess weight gain in pregnancy (GWG) $[13,15,20]$.

Various scientific societies list pre-pregnancy obesity among the factors of moderate or high risk of preeclampsia. However, it is not yet established how obesity affects the various phenotypes of hypertension. Some studies have linked increases in BMI to the development of late-onset PE, but not to early-onset PE; however, other studies have not confirmed these results [21]. The availability in the literature of a much larger number of studies which only deal with women developing preeclampsia (PE), as compared to studies covering isolated gestational hypertension (GH), makes it difficult to identify the differences between $\mathrm{PE}$ and $\mathrm{GH}$. Both of these forms of hypertension in pregnancy require research, as both are associated with poorer neonatal outcomes, as compared to the pregnancy outcomes of normotensive women $[7,13,18,22]$.

The results based on the calculation of the odds ratios and/or predictive indicators available in the literature have their drawbacks. In the case of the odds ratio, a disadvantage is the inability to compare this measure between different variables, e.g., between continuous variables expressed in different units. Area under curve (AUC) in multivariate regression models can be compared for any variable; however, AUC has no good clinical interpretation. In addition, assessing markers with these measures omits those with missing data, leading to results for slightly different groups. All this makes it difficult 
to compare the hierarchy of factors. Many studies have shown that adding more markers to the predictive model improves the quality of the prediction or classification to the ill and the healthy group of patients. However, this does not explain which factor in the multivariate model is the strongest.

Our aim was to investigate in a joint cohort how important role pre-pregnancy obesity of the mother plays in the likelihood of developing isolated gestational hypertension (GH) and preeclampsia (PE), compared to the role of other risk factors. Our analysis was based on the measurement of several statistical indicators, in the evaluation of multivariate probability models. In order to broaden the assessment of the quality of the prediction of potential GH and PE risk markers, in addition to AUC, we used two newer coefficients: Integrated Discrimination Improvement (IDI) and Net Reclassification Improvement (NRI). The IDI measures the mean change in disease probability when a new marker is added to the model. The NRI, on the other hand, provides a clinically very favorable interpretation by calculating the percentage of persons in whom the addition of the marker under examination improves or worsens the prediction (classification). Missing data were treated as an additional category, and each analysis was based on the same dataset [23-25]. We have not found a similar study in the literature.

We studied a cohort of pregnant women prospectively recruited during the first trimester, when pregnancy outcomes were unknown.

\section{Materials and Methods}

The study was conducted in accordance with the Helsinki Declaration. It was registered and approved by the Bioethics Committee in Poznań, Poland (Medical University No. 769/15). All the women recruited for this study expressed their informed consent before completing the survey questionnaire.

\subsection{Participants and Methods}

The current analysis is based on the data from a prospectively recruited cohort of pregnant women. The participants were recruited in 2015-2016. The research center was the Gynecology and Obstetrics Clinical Hospital of the Medical University of Poznań, Poland. This center is a third-level hospital in the field of obstetrics.

The recruitment process took place at the central laboratory of this clinical hospital. Information about the study was displayed in a prominent place and was available to any woman who voluntarily reported for laboratory tests. The eligibility criteria included the following: (1) being a Caucasian woman from the Wielkopolska region, which ruled out the influence of ethnic differences (an important risk factor for many diseases), and matched the study groups in terms of the quality of prenatal care; (2) aged 18-45 years at conception; (3) with a single pregnancy; (4) gestational age of 10-14 weeks; (5) the absence of chronic diseases, especially hypertension and diabetes mellitus, as well as kidney and/or liver dysfunction, and the absence of any immunological and inflammatory diseases and thromboembolism; and (6) the absence of fetal defects and the birth of a (phenotypically) normal child of $\geq 25$ th week of gestation.

The recruitment was the first stage of the study. The participants completed the research questionnaire (they did it on their own, in the presence of a midwife). The questionnaire was used to collect the information about the current pregnancy and previous pregnancies, accompanying symptoms, supplementation with folic acid, and other multivitamin preparations (typically recommended for pregnant women), as well as the use of other drugs and stimulants (the women informed us about their smoking before pregnancy and at the time of recruitment, and no participants reported alcohol consumption during pregnancy). Sociodemographic data were recorded, as well. The questionnaire also included questions about family health history (including chronic hypertension). The questionnaire also asked about the consumption of several groups of food products (number of servings per week), but it was not a standardized nutritional questionnaire, and its main purpose was to identify the women using special diets; all the participants reported a mixed diet 
during the first trimester of pregnancy, and several women reported having followed a vegetarian diet in the past.

In the second stage, after delivery, information was collected on the course of pregnancy, possible complications in the mother, and the results of the newborn. The data were taken from medical records. A change in diet was observed in the women with diagnosed pregnancy-induced hypertension or gestational diabetes (women with hypertension used a low-sodium diet).

All 1300 women who expressed their willingness to participate in the study and met the criteria were invited to take part. Forth-eight women were excluded due to miscarriage $<20$ th week, delivery $<25$ th week, diagnosis of the child's defect, severe infection during pregnancy, thromboembolism, arterial hypertension before the 20th week, diabetes before the 18th week, and lack of cooperation. In total, 340 women were also excluded due to their incomplete data.

The primary cohort for which the data were analyzed consisted of 912 participants. In this analysis, we examined women who developed pregnancy-induced hypertension during pregnancy, including preeclampsia, PE $(n=24)$ and isolated gestational hypertension, $\mathrm{GH}(n=113)$, and those who remained normotensive $(n=775)$.

In the current analysis, the relationships between clinical factors and the development of each of the forms of pregnancy-induced hypertension, preeclampsia, and gestational hypertension were investigated.

\subsection{Definitions}

The definition of pregnancy-induced hypertension was adopted according to the guidelines of national and European scientific societies as systolic and diastolic blood pressure $\geq 140 \mathrm{mmHg}$ and $\geq 90 \mathrm{mmHg}$ (respectively) obtained in at least two measurements $4 \mathrm{~h}$ apart, developing after the 20th week of gestation in women without previous symptoms of hypertension (measured with an oscilometric device in a sitting position) [13]. Preeclampsia (PE) was diagnosed when hypertension was accompanied by de novo development of one organ system disorder (such as renal dysfunction, hepatic dysfunction, thrombocytopenia, cerebral or visual symptoms, and/or pulmonary edema). In this cohort only proteinuria was found in all the PE cases ( $\geq 0.3 \mathrm{~g} / \mathrm{L})$ [26]. Gestational hypertension (GH) was diagnosed when only hypertension was detected. Blood pressure (systolic and diastolic) before pregnancy was self-reported. Blood pressure was measured in hospital, and values after childbirth (measured on the postpartum ward) were taken for this analysis.

In gestation week 24-28th, an oral glucose tolerance test ( $2 \mathrm{~h}$ test, for $75 \mathrm{~g}$ of glucose) was performed to diagnose gestational diabetes mellitus (GDM). GDM-1 was diagnosed when dietary treatment was sufficient to balance the plasma sugar level. GDM-2 diabetes was diagnosed when the normalization of glycaemia required treatment with insulin.

Gestational age was determined using ultrasound examination (USG). Information on the diagnosis of intrauterine growth restriction (IUGR) was found in medical records, and the diagnosis was based on ultrasound examination during pregnancy. Newborn weight was measured conventionally (in grams) immediately after childbirth using an automatic device. Birth weight percentiles were estimated for gender and gestational age in the study population (based on percentile grids).

\subsection{Potential Predictors, Independent Variables}

In the present analysis, we examined a number of clinical factors identified in the literature as potential risk factors for pregnancy-induced hypertension in order to compare them with the results obtained for the pre-pregnancy body mass index (BMI) [13].

Maternal age (defined as completed age in years at conception) was assessed as a continuous and categorical (c) (category 18-24, 25-29, 30-34, 35-39 and $\geq 40$ years).

The number of previous deliveries was assessed as a categorical variable (c) $(0,1,2, \geq 3$ deliveries). Primiparity was assessed as a dichotomous variable (primiparity vs. multiparity). 
Interpregnancy interval was assessed as a categorical variable (c): primigravida women, 1, 2, 3-5, $6-10, \geq 11$ years, and the category "unknown" (cases of missing data).

Pre-pregnancy BMI was calculated as the quotient of pre-pregnancy weight in kg (self-reported) and height in meters (from medical records) squared. BMI was assessed as: a continuous variable $\left(\mathrm{kg} / \mathrm{m}^{2}\right)$, or a categorical variable (c) (with the following categories: $<18.5,18.5-24.9,25.0-29.9$ and $\geq 30 \mathrm{~kg} / \mathrm{m}^{2}$ for underweight, normal weight, overweight and obesity, respectively), or dichotomous variables ( $\geq 25 \mathrm{~kg} / \mathrm{m}^{2}$ vs. $<25 \mathrm{~kg} / \mathrm{m}^{2}$, and $\geq 30 \mathrm{~kg} / \mathrm{m}^{2}$ vs. $<30 \mathrm{~kg} / \mathrm{m}^{2}$ ).

Height $(\mathrm{cm})$ and pre-pregnancy weight $(\mathrm{kg})$ were assessed as continuous variables.

Gestational weight gain (GWG) was calculated as the difference between the weight before delivery (from medical records) and the pre-pregnancy weight (self-reported). GWG was assessed as a continuous variable $(\mathrm{kg})$ and categorical variable (c), according to the 2009 Institute of Medicine (IOM) recommendations: above, below, and in the range [7]. GWG was also assessed as a dichotomous variables: GWB above the range vs. others; GWG $>10 \mathrm{~kg}$ vs. $<10 \mathrm{~kg}$; and GWG $>15 \mathrm{~kg}$ vs. $<15 \mathrm{~kg}$ ).

Prior GH/PE, infertility treatment, in vitro fertilization (IVF), hypothyroidism, no supplementation with folic acid in 1st trimester (self-reported), no supplementation with multivitamin (multivitamin and multi-microelement) preparations in 2-3 trimester, urogenital infection (in 2-3 trimester and smoking in I trimester, were assessed as dichotomous variables ("yes" vs. "others").

Family history of (chronic) hypertension was assessed as a categorical (c) variable including paternal and/or maternal hypertension, hypertension in the family but not in the father/mother, and no hypertension in the family. Hypertension in the mother was also assessed as a categorial (c) variable including maternal hypertension, hypertension in the family but not in the mother, and no hypertension in the family. Moreover, hypertension in the father was assessed as a categorial (c) variable including paternal hypertension, hypertension in family but not in the father, and no hypertension in the family.

Education was assessed as a dichotomous variable: education of $<12$ years (primary and vocational) vs. other (secondary and tertiary education, and the category "unknown" for no data).

Financial status was assessed as a dichotomous variable. The categories were grades on the 5-point Likert scale, given to answers to the question "is your household's financial status sufficient for your needs" (answer, 1 "definitely No"; answer, 2 "rather No"; answer 3, "hard to say"; answer, 4 "rather Yes"; answer, 5 "definitely Yes", and category "unknown" for no data). The dichotomous analysis included: lower financial status (answers $1+2+3$ ) vs. answers $4+5$, and the category "unknown" for no data.

Place of residence was assessed as a categorical variable (c): village, small town $<50,000$ inhabitants, and large city $>50,000$ inhabitants.

\subsection{Statistical Analyses}

The investigated independent variables (potential predictors) were described using mean values and standard deviation (SD) and medians (for continuous variables) or by number and percentage (for categorical variables). The normal distribution of continuous variables was assessed with the Shapiro-Wilk test. Comparisons of the independent variables between the control (normotensive) group and the case group (GH or PE) were performed using the Mann-Whitney test (for comparing continuous variables) and the Chi-squared test or Fisher exact test (for comparing categorical variables); statistical significance ( $p$-value) is given for each analysis.

Risk factors were assessed as categorical (c) and/or dichotomous and/or continuous variables (with the measurement units including year, $\mathrm{kg}, \mathrm{kg} / \mathrm{m}^{2}$ and $\mathrm{cm}$ ). For some risk factors, all three forms of variables were assessed. For missing data in categorical variables, a special category labeled "unknown" was created, allowing us to examine the participants with missing data and evaluate all the variables on the full set of 912 participants.

The analysis of categories (c) can be advantageous because categories do not assume any shape of dependence, there is only a division into categories. When examining categories (c), the shape of the 
relationship will be discovered in the analysis and used for prediction. This is especially important in some situations, where both lower and higher categories/values increase the odds ratios of the disease.

To achieve the main aim of the study, this analysis assessed the degree of influence of each of the maternal factors tested on GH or PE prediction. All the analyses were performed based on logistic regression models. First, crude odds ratios (ORs) for the disease (GH or PE) incidence (along with 95\% confidence intervals) were determined for each maternal factor (independent variable) by means of unidimensional logistic regression; the statistical significance of OR was reported, as determined by Wald's test ( $p$-value).

Subsequently, multi-factor predictive regression models (separately for GH and PE) were built. A small basic regression model was built, which included age and primiparity. Subsequent models were extended, and one additional (tested) variable was added to the base model. Three prediction indexes were used to assess the improvement in prediction (change in disease probability) in the subsequent extended multivariate models (compared to the base model): Integrated Discrimination Improvement (IDI), Net Reclassification Improvement (NRI), and area under receiver operating characteristic curve (AUC under ROC curve) of the basic and extended model. For each of the three indicators, 95\% confidence intervals were calculated, and their statistical significance ( $p$-value) was checked. High and statistically significant values obtained for the difference of AUC and for IDI and NRI prove good predictive ability of the variable added to the basic regression model [23-25].

AUC is a known prediction factor in regression models; the greater the difference between the AUC of the extended model and the AUC of the base model, the greater the improvement in the prediction when a new variable is added to the model. The IDI index shows the difference between the value of the mean change in the predicted probability between the group of sick women and the group of healthy women. The NRI index focuses on the reclassification table describing the number of women in whom an upward or downward shift in the disease probability value occurred after a new factor had been added to the model.

The final stage of the analysis was to determine the order (hierarchy) of the examined maternal factors for each of these measures separately (AUC of the extended model, as well as IDI and NRI) assigning the first place to the variable with the highest measure and the last place to the variable with the lowest measure. Finally, the sum of the sequences obtained from these three measures was calculated, and a new order of significance of the maternal factors was given, highlighting those factors which showed the greatest improvement in prediction in the analyses conducted (ranking first in the sequences).

The $p$-value in each analysis was considered statistically significant when its value was less than 0.05. The analyses were performed by using PQstat v1.8.0 (PQstat Software, Poznań, Poland) software.

\section{Results}

The whole group consisted of 912 women with a single pregnancy who had no chronic diseases. In the entire cohort (Supplementary Materials Table S1), there were $271(29.7 \%)$ women with a BMI $\left.\geq 25 \mathrm{~kg} / \mathrm{m}^{2}\right)$, among them 98 (10.8\%) obese women, including obesity I, II, and III (7.7\%, 2.7\%, and 0.4\%, respectively). The percentage of women with GWG above the IOM recommendation range was 36.8\%, but for the women with excessive pre-pregnancy BMI, it was 59.0\%, compared to $28.7 \%$ for the women with normal BMI (Supplementary Materials Table S1).

Table 1 and Supplementary Materials Table S2 present the characteristics of the control and case group. Compared to normotensive women, the women who developed hypertension during pregnancy (gestational hypertension (GH) or preeclampsia (PE)) had higher mean pre-pregnancy BMI, were older, were more often primiparas, more frequently they reported GH/PE in previous pregnancies, were more often treated due to infertility, had a higher mean interpregnancy interval, smoked more often, more frequently displayed lower socioeconomic indicators, and more often reported a family history of chronic hypertension (in the mother or father). 
Importantly, cases (of GH and PE) statistically resulted in significantly worse pregnancy outcomes (lower gestational age of newborns, lower birth weight, and more cases of intrauterine growth restriction (IUGR)) than in normotensive women, but unfavorable pregnancy outcomes in women with PE were more strongly expressed. Preterm delivery $<37$ th and $<34$ th week was significantly more frequent in the women with hypertension, especially in PE cases ( $54.2 \%$ and $25.0 \%$, respectively), compared to normotensive women (5.3\% and $1.3 \%$, respectively). GDM occurred more frequently in $\mathrm{GH}$ and PE cases, as compared to controls, but the difference was statistically insignificant. Fetal sex was not associated with cases of hypertension.

Table 1. Basic characteristics of normotensive women and women developing hypertension in pregnancy.

\begin{tabular}{|c|c|c|c|c|c|}
\hline & $\begin{array}{l}\text { Controls } \\
(n=775)\end{array}$ & $\begin{array}{c}\text { GH } \\
(n=113)\end{array}$ & & $\begin{array}{c}\text { PE } \\
(n=24)\end{array}$ & \\
\hline Variables & $\begin{array}{c}\text { Mean (SD) } \\
\text { or } n(\%)\end{array}$ & $\begin{array}{l}\text { Mean (SD) } \\
\text { or } n(\%)\end{array}$ & $p^{*}$ & $\begin{array}{c}\text { Mean (SD) } \\
\text { or } n(\%)\end{array}$ & $p^{*}$ \\
\hline Maternal age (years) & $33.5(4.8)$ & $35.0(4.3)$ & 0.005 & $34.1(5.0)$ & 0.434 \\
\hline Primiparous women & $318(41.0 \%)$ & $53(46.9 \%)$ & 0.237 & $12(50.0 \%)$ & 0.380 \\
\hline Prior GH/PE & $4(0.5 \%)$ & $12(10.6 \%)$ & $<0.001$ & $3(12.5 \%)$ & $<0.001$ \\
\hline Aspirin (for prophylaxis) & $7(0.9 \%)$ & $2(1.8 \%)$ & 0.390 & $2(8.3 \%)$ & $<0.001$ \\
\hline Infertility treatment & $29(3.7 \%)$ & $8(7.1 \%)$ & 0.097 & $3(12.5 \%)$ & 0.031 \\
\hline Interpregnancy interval ** & $4.4(4.0)$ & $5.6(4.3)$ & 0.031 & $7.4(5.3)$ & 0.023 \\
\hline Smoking in I trimester & $37(4.8 \%)$ & $17(15.0 \%)$ & $<0.001$ & $3(12.5 \%)$ & 0.084 \\
\hline Education $<12$ years ${ }^{* *}$ & $48(7 \%) 1$ & $16(16.3 \%)$ & 0.002 & $6(27.3 \%)$ & $<0.001$ \\
\hline $\begin{array}{l}\text { Lower financial status ** } \\
\text { Family history }\end{array}$ & $95(26.1 \%)$ & $28(43.8 \%)$ & $<0.001$ & $8(57.1 \%)$ & 0.007 \\
\hline Hypertension in the mother & $137(17.8 \%)$ & $31(27.7 \%)$ & 0.013 & $11(45.8 \%)$ & $<0.001$ \\
\hline Pre-pregnancy BMI $\left(\mathrm{kg} / \mathrm{m}^{2}\right)$ & $23.3(4.1)$ & $26.7(5.3)$ & $<0.001$ & $26.5(6.2)$ & 0.008 \\
\hline GWG $(\mathrm{kg})$ & $13.4(5.3)$ & $14.6(8.0)$ & 0.115 & $15.1(8.2)$ & 0.612 \\
\hline Fetal sex, daughter & $370(47.7 \%)$ & $58(51.3 \%)$ & 0.476 & $11(45.8 \%)$ & 0.853 \\
\hline $\begin{array}{l}\text { Gestational age at childbirth } \\
\text { (week) }\end{array}$ & $38.9(1.6)$ & $38.3(2.2)$ & 0.016 & $35.1(3.7)$ & $<0.001$ \\
\hline Preterm birth $<37$ th week & $41(5.3 \%)$ & $11(9.7 \%)$ & 0.060 & $13(54.2 \%)$ & $<0.001$ \\
\hline Preterm birth $<34$ th week & $10(1.3 \%)$ & $7(6.2 \%)$ & $<0.001$ & $6(25.0 \%)$ & $<0.001$ \\
\hline Newborn birthweight (g) & $\begin{array}{l}3416.5 \\
(511.7)\end{array}$ & $\begin{array}{l}3174.1 \\
(734.3)\end{array}$ & 0.001 & $\begin{array}{l}2294.2 \\
(927.5)\end{array}$ & $<0.001$ \\
\hline IUGR cases & $11(1.4 \%)$ & $6(5.5 \%)$ & 0.004 & $4(18.2 \%)$ & $<0.001$ \\
\hline Cesarean section & $306(39.5 \%)$ & $54(47.8 \%)$ & 0.093 & $22(91.7 \%)$ & $<0.001$ \\
\hline GDM & $121(15.6 \%)$ & $22(19.5 \%)$ & 0.298 & $3(12.5 \%)$ & 0.678 \\
\hline Gestational diabetes mellitus & $121(15.6 \%)$ & $22(19.5 \%)$ & 0.298 & $3(12.5 \%)$ & 0.678 \\
\hline PE beginning <32th week & & & & $7(29.2 \%)$ & \\
\hline PE beginning $\geq 34$ th week & - & - & - & $13(54.2 \%)$ & - \\
\hline \multicolumn{6}{|l|}{ Blood pressure before pregnancy } \\
\hline Systolic $(\mathrm{mmHg})$ & $104.9(10.4)$ & $123.5(8.5)$ & $<0.001$ & $123.3(8.7)$ & $<0.001$ \\
\hline Diastolic $(\mathrm{mmHg})$ & $64.5(8.7)$ & $76.8(7.7)$ & $<0.001$ & $78.1(8.6)$ & $<0.001$ \\
\hline \multicolumn{6}{|l|}{ Blood pressure after delivery } \\
\hline Systolic $(\mathrm{mmHg})$ & $107.9(10.8)$ & $157.2(17.6)$ & $<0.001$ & $170.3(17.5)$ & $<0.001$ \\
\hline Diastolic (mmHg) & $66.8(8.8)$ & $99.6(9.3)$ & $<0.001$ & $106.8(15.8)$ & $<0.001$ \\
\hline
\end{tabular}

* The Mann-Whitney U test was used for comparisons of continuous variables, and the Pearson chi-square test (or Fisher exact test when Cochran assumption was not met) for binomial categories was used ( $p<0.05$ was assumed to be significant); ** for available data. Controls = normotensive women; GH, gestational hypertension; PE, preeclampsia; BMI, body mass index; GWG, gestational weight gain; IUGR, Intrauterine Growth Restriction; GDM, gestational diabetes mellitus. 
Table 2 and Supplementary Materials Table S3 show the odds ratios of gestational hypertension (GH) and preeclampsia (PE) for many maternal characteristics. An increase in BMI by $1 \mathrm{~kg} / \mathrm{m}^{2} \mathrm{resulted}$ in a statistically significant increase in GH odds ratios by $16 \%$ and an increase in PE odds ratios by $15 \%$.

Among the categorical variables, the $\mathrm{GH}$ odds ratios were the highest for the following (in the order of importance): prior $\mathrm{GH} / \mathrm{PE}$, pre-pregnancy $\mathrm{BMI} \geq 30 \mathrm{~kg} / \mathrm{m}^{2}$, smoking in first trimester, maternal age $\geq 40$ years, lower education, and others.

A different hierarchy was found in the PE study. The PE odds ratios were the highest for the following (in the order of importance): GH/PE, pre-pregnancy BMI $\geq 30 \mathrm{~kg} / \mathrm{m}^{2}$, interpregnancy interval, education $<12$ years, family history with chronic hypertension in the mother, and others. The effect of gestational diabetes, lower maternal height, and fetal sex was insignificant.

The similar profiles were found after being adjusted for maternal age and primiparity (AOR-a), and pre-pregnancy BMI (AOR-b) (Supplementary Materials Table S3).

Table 2. The odds ratios of gestational hypertension (GH) and preeclampsia (PE) for selected maternal characteristics.

\begin{tabular}{|c|c|c|c|c|}
\hline Variables & $\begin{array}{c}\text { GH } \\
\text { OR }(95 \% \text { CI }) *\end{array}$ & $p^{* *}$ & $\begin{array}{c}\text { PE } \\
\text { OR }(95 \% \mathrm{CI}) *\end{array}$ & $p^{* *}$ \\
\hline \multicolumn{5}{|l|}{ Continuous variables: } \\
\hline Pre-pregnancy BMI $\left(\mathrm{kg} / \mathrm{m}^{2}\right)$ & $1.16(1.11-1.21)$ & $<0.001$ & $1.15(1.06-1.24)$ & $<0.001$ \\
\hline Maternal age (years) & $1.07(1.03-1.12)$ & 0.003 & $1.03(0.94-1.12)$ & 0.539 \\
\hline GWG $(\mathrm{kg})$ & $1.04(1.00-1.07)$ & 0.040 & $1.06(0.98-1.14)$ & 0.145 \\
\hline \multicolumn{5}{|l|}{ Other variables: } \\
\hline Prior GH/PE (vs. others) & $22.90(7.3-72.4)$ & $<0.001$ & $\begin{array}{c}27.54 \\
(5.8-130.8)\end{array}$ & $<0.001$ \\
\hline $\mathrm{BMI} \geq 30 \mathrm{~kg} / \mathrm{m}^{2}$ (vs. normal BMI) & $5.60(3.32-9.43)$ & $<0.001$ & $\begin{array}{c}9.21 \\
(3.52-24.11)\end{array}$ & $<0.001$ \\
\hline Smoking in I trimester (vs. others) & $3.53(1.92-6.52)$ & $<0.001$ & $2.85(0.81-9.99)$ & 0.102 \\
\hline Age $\geq 40$ years (vs. 25-29 years) & $3.23(1.41-7.38)$ & 0.005 & $1.11(0.1-12.49)$ & 0.933 \\
\hline Education $<12$ years vs. others ${ }^{* *}$ & $2.50(1.37-4.57)$ & 0.003 & $\begin{array}{c}5.05 \\
(1.92-13.31)\end{array}$ & 0.001 \\
\hline GWG above the range (vs. normal) & $2.45(1.53-3.92)$ & $<0.001$ & $1.57(0.62-3.97)$ & 0.337 \\
\hline Financial status $(1-2-3)$ vs. others ** & $2.36(1.46-3.80)$ & $<0.001$ & $3.58(1.49-8.59)$ & 0.004 \\
\hline Urogenital infection (vs. others) & $2.12(1.31-3.43)$ & 0.002 & $0.61(0.14-2.65)$ & 0.513 \\
\hline No multivitamins (vs. others) \# & $2.11(1.41-3.15)$ & $<0.001$ & $0.90(0.39-2.08)$ & 0.806 \\
\hline \multicolumn{5}{|l|}{ Family history of Hypertension (H) } \\
\hline $\mathrm{H}$ in the father (vs. controls) $* * *$ & $2.06(1.29-3.28)$ & 0.003 & $1.84(0.62-5.47)$ & 0.274 \\
\hline $\mathrm{H}$ in the mother (vs. controls) ${ }^{* * *}$ & $1.90(1.18-3.06)$ & 0.008 & $3.98(1.66-9.57)$ & 0.002 \\
\hline \multicolumn{5}{|l|}{ Interpregnancy interval (years) } \\
\hline$\geq 11$ years (vs. 1 year) & $2.02(0.90-4.58)$ & 0.091 & $\begin{array}{c}6.63 \\
(1.18-37.29)\end{array}$ & 0.032 \\
\hline Hypothyroidism (vs. others) & $2.01(1.23-3.29)$ & 0.006 & $2.36(0.91-6.09)$ & 0.076 \\
\hline Infertility treatment (vs. others) & $1.96(0.87-4.4)$ & 0.103 & $\begin{array}{c}3.68 \\
(1.04-13.03)\end{array}$ & 0.044 \\
\hline In vitro fertilization (vs. others) & $1.92(0.76-4.84)$ & 0.167 & $\begin{array}{c}3.11 \\
(0.69-14.06)\end{array}$ & 0.140 \\
\hline Primiparity (vs. multiparity) & $1.27(0.85-1.89)$ & 0.238 & $1.22(0.54-2.75)$ & 0.638 \\
\hline
\end{tabular}

* OR, crude odds ratios (and 95\% confidence intervals) calculated in unidimensional logistic regression;

** $p$-value $<0.05$ was statistically significant; ${ }^{* * *}$ controls $=$ women without family history of hypertension. \# No multivitamins supplementation in 2nd-3rd trimester. GH, gestational hypertension; PE, preeclampsia; BMI, body mass index; GWG, gestational weight gain; $\mathrm{H}$, hypertension. 
Table 3 presents AUC values for predicting GH and PE calculated for continuous variables and for the basic multi-factor predictive model (maternal age + primiparity). In the GH and PE study, the AUC of the pre-pregnancy BMI model was higher (and more statistically significant) when compared to the other model AUC.

Table 3. Area under curve (AUC) values for predicting GH and PE.

\begin{tabular}{ccccc}
\hline Variables & GH & \multirow{2}{*}{$\boldsymbol{p}^{*}$} & PE & \multirow{2}{*}{ AUC } \\
\hline AUC & 0.698 & $<0.001$ & 0.660 & 0.008 \\
Pre-pregnancy BMI $\left(\mathrm{kg} / \mathrm{m}^{2}\right)$ & 0.581 & 0.005 & 0.547 & 0.435 \\
Maternal age (years) & 0.546 & 0.115 & 0.530 & 0.613 \\
GWG (kg) & 0.600 & 0.001 & 0.539 & 0.520 \\
\hline
\end{tabular}

* A $p$-value < 0.05 was statistically significant. GH, gestational hypertension; PE, preeclampsia; AUC, area under receiver operating characteristic curve; BMI, body mass index; GWG, gestational weight gain.

Tables 4 and 5 show the results for three prediction indexes (AUC, IDI, and NRI) in predicting GH or PE after the extension of the underlying predictive model (maternal age + primiparity). The indexes, confidence intervals, and $p$-value, as well as the percentage of patients reclassified upward and downward, are presented in Supplementary Materials Tables S4-S6.

Table 4 shows the results for the gestational hypertension $(\mathrm{GH})$ prediction. All AUC values of the extended models were statistically significant $(p<0.001)$, and the $p$-value is presented for comparing the AUC of the extended models with the AUC of the base model. The area under the curve increased most strongly when we added BMI $\left(\mathrm{kg} / \mathrm{m}^{2}\right)$ as a continuous variable (AUC $\left.=0.716\right)$ to the base model $(\mathrm{AUC}=0.600)$. Other forms of pre-pregnancy BMI are also high in the table, including the BMI category $\geq 25 \mathrm{~kg} / \mathrm{m}^{2}$ (AUC = 0.685). They are followed by BMI $\geq 30 \mathrm{~kg} / \mathrm{m}^{2}$ and prior $\mathrm{GH} / \mathrm{PE}$, as well as GWG expressed in categories (c) (identical to the result for GWG above the IOM recommendations).

Similarly, the BMI index showed a high predictive value also in the NRI examination. NRI $=0.571$ was obtained for both BMI examined as a continuous variable and BMI $\geq 25 \mathrm{~kg} / \mathrm{m}^{2}$. At the same time, it should be noted that adding these variables to the model improves the quality of classification to a greater extent for healthy women NRI $(0)=49.2 \%$ than for the sick ones NRI $(1)=8 \%$ (complete results in Supplementary Materials Table S5). The IDI index showed a similar hierarchy of maternal factors, but the highest value of the IDI index was obtained for prior GH/PE (IDI = 0.068) (Supplementary Materials Table S6).

Table 5 shows the results for predicting preeclampsia (PE). The AUC values of the extended models were statistically significant after adding the variables listed in the first half of the table to the prior GH/PE variable. The table presents the $p$-value for comparing the AUC of the extended models to the AUC of the base model. The area under the curve increased most strongly when we added BMI as a categorical variable $(\mathrm{c})(\mathrm{AUC}=0.726)$ or family history with hypertension in the mother (c) (AUC $=0.717)$ to the base model (AUC $=539$ ). Other forms of pre-pregnancy BMI are also high in the table, with $\mathrm{BMI} \geq 30 \mathrm{~kg} / \mathrm{m}^{2}$ (AUC $=0.703$ ) ranked highest among the categories. The following AUC values in the table were obtained after extending the model with $\mathrm{BMI} \geq 25 \mathrm{~kg} / \mathrm{m}^{2}$, with $\mathrm{BMI}$ as a continuous variable and hypertension in the father (c).

Adding BMI to the prediction model, as well as adding family history with hypertension in the mother (c), also allowed us to obtain high NRI coefficients, which, as can be seen in a more detailed analysis of these coefficients, resulted mainly from the improvement of the prediction for the healthy women (positive and high NRI (0)), with a slight worsening of the prediction for the sick women (low and negative NRI (1)) (Supplementary Materials Table S5). The IDI index showed a similar hierarchy of maternal factors, but the highest value of the IDI index was obtained for prior GH/PE (IDI = 0.050) (Supplementary Materials Table S6). 
Table 4. Values of the three predictive indicators in the extended multivariate models in the assessment of the probability of gestational hypertension (GH).

\begin{tabular}{|c|c|c|c|c|c|c|}
\hline \multirow{3}{*}{$\begin{array}{c}\text { Base Model } \\
\text { (Maternal Age + Primiparity) } \\
\text { Extended Models } \\
\text { (Base Model + Listed Variables) }\end{array}$} & \multicolumn{5}{|c|}{ GH } & \multirow[b]{3}{*}{$\begin{array}{c}p \text {-Value * } \\
\text { (Extended vs. Base) }\end{array}$} \\
\hline & AUC Base 0.600 & & & & & \\
\hline & AUC Extended & $\begin{array}{c}p \text {-Value * } \\
\text { (Extended vs. Base) }\end{array}$ & IDI & $\begin{array}{c}p \text {-Value * } \\
\text { (Extended vs. Base) }\end{array}$ & NRI & \\
\hline Pre-pregnancy BMI $\left(\mathrm{kg} / \mathrm{m}^{2}\right)$ & 0.716 & $<0.001$ & 0.064 & $<0.001$ & 0.542 & $<0.001$ \\
\hline Pre-pregnancy BMI (c) & 0.704 & $<0.001$ & 0.058 & $<0.001$ & 0.571 & $<0.001$ \\
\hline Pre-pregnancy weight (kg) & 0.697 & $<0.001$ & 0.044 & $<0.001$ & 0.544 & $<0.001$ \\
\hline Pre-pregnancy BMI $\geq 25 \mathrm{~kg} / \mathrm{m}^{2}$ & 0.685 & 0.001 & 0.041 & $<0.001$ & 0.571 & $<0.001$ \\
\hline Pre-pregnancy BMI $\geq 30 \mathrm{~kg} / \mathrm{m}^{2}$ & 0.663 & 0.002 & 0.045 & $<0.001$ & 0.399 & $<0.001$ \\
\hline Prior GH/PE & 0.656 & 0.002 & 0.068 & $<0.001$ & 0.433 & $<0.001$ \\
\hline GWG (c) & 0.653 & 0.024 & 0.027 & $<0.001$ & 0.419 & $<0.001$ \\
\hline Financial status & 0.648 & 0.022 & 0.015 & 0.007 & 0.250 & 0.003 \\
\hline No multivitamins & 0.646 & 0.039 & 0.016 & 0.001 & 0.368 & $<0.001$ \\
\hline Smoking in I trimester & 0.646 & 0.025 & 0.024 & 0.003 & 0.205 & 0.003 \\
\hline Education $<12$ years & 0.643 & 0.018 & 0.01 & 0.043 & 0.159 & 0.019 \\
\hline Family history; $\mathrm{H}$ in the mother (c) & 0.639 & 0.034 & 0.004 & 0.19 & 0.236 & 0.019 \\
\hline Family history; $\mathrm{H}$ in the father (c) & 0.638 & 0.052 & 0.008 & 0.046 & 0.279 & 0.005 \\
\hline No folic acid supplementation & 0.634 & 0.101 & 0.013 & $<0.001$ & 0.312 & $<0.001$ \\
\hline Urogenital infection & 0.632 & 0.075 & 0.01 & 0.022 & 0.220 & 0.009 \\
\hline Family history of Hypertension & 0.631 & 0.064 & 0.004 & 0.194 & 0.236 & 0.019 \\
\hline Interpregnancy interval (c) & 0.619 & 0.166 & 0.004 & 0.086 & -0.014 & 0.891 \\
\hline Hypothyroidism & 0.618 & 0.253 & 0.008 & 0.032 & 0.195 & 0.017 \\
\hline GWG $(\mathrm{kg})$ & 0.616 & 0.402 & 0.011 & 0.009 & 0.149 & 0.139 \\
\hline Maternal height $(\mathrm{cm})$ & 0.613 & 0.22 & 0.003 & 0.137 & 0.125 & 0.213 \\
\hline Place of residence $(\mathrm{c})$ & 0.611 & 0.318 & 0.002 & 0.238 & 0.144 & 0.094 \\
\hline GWG $>15 \mathrm{~kg}$ & 0.607 & 0.551 & 0.004 & 0.077 & 0.113 & 0.248 \\
\hline Treatment of infertility & 0.601 & 0.621 & 0.0007 & 0.562 & -0.074 & 0.386 \\
\hline In vitro fertilization & 0.6 & 0.925 & 0.0005 & 0.6 & -0.12 & 0.151 \\
\hline GWG > $10 \mathrm{~kg}$ & 0.598 & 0.599 & 0.0003 & 0.454 & -0.011 & 0.903 \\
\hline
\end{tabular}

* A $p$-value < 0.05 was statistically significant. AUC, area under receiver operating characteristic curve; IDI, Integrated Discrimination Improvement; NRI, Net Reclassification Improvement;

(c): categories of independent variables (described in the Methodology); BMI, body mass index; GWG, gestational weight gain; $\mathrm{H}$, hypertension in family history. 
Table 5. Values of the three predictive indicators in the extended multivariate models in the assessment of the probability of preeclampsia (PE).

\begin{tabular}{|c|c|c|c|c|c|c|}
\hline & & & PE & & & \\
\hline $\begin{array}{c}\text { Base Model } \\
\text { (Maternal Age + Primiparity) }\end{array}$ & AUC Base 0.539 & & & & & \\
\hline $\begin{array}{c}\text { Extended Models } \\
\text { (Base Model + Listed Variables) }\end{array}$ & AUC Extended & $\begin{array}{l}p \text {-Value *(Extended } \\
\text { vs. Base) }\end{array}$ & IDI & $\begin{array}{c}p \text {-Value * } \\
\text { (Extended vs. Base) }\end{array}$ & NRI & $\begin{array}{c}p \text {-Value * } \\
\text { (Extended vs. Base) }\end{array}$ \\
\hline Pre-pregnancy BMI (c) & 0.726 & 0.017 & 0.034 & 0.002 & 0.688 & 0.001 \\
\hline Family history of $\mathrm{H}$ in the mother (c) & 0.717 & 0.009 & 0.013 & 0.020 & 0.563 & 0.006 \\
\hline Pre-pregnancy BMI $\geq 30 \mathrm{~kg} / \mathrm{m}^{2}$ & 0.703 & 0.009 & 0.032 & 0.004 & 0.600 & 0.002 \\
\hline Pre-pregnancy BMI $\geq 25 \mathrm{~kg} / \mathrm{m}^{2}$ & 0.679 & 0.042 & 0.012 & 0.011 & 0.575 & 0.005 \\
\hline Pre-pregnancy BMI $\left(\mathrm{kg} / \mathrm{m}^{2}\right)$ & 0.678 & 0.107 & 0.02 & 0.019 & 0.510 & 0.013 \\
\hline Family history of $\mathrm{H}$ in the father (c) & 0.658 & 0.094 & 0.007 & 0.059 & 0.447 & 0.029 \\
\hline Financial status & 0.648 & 0.068 & 0.012 & 0.039 & 0.422 & 0.030 \\
\hline Interpregnancy interval (c) & 0.646 & 0.138 & 0.007 & 0.072 & 0.405 & 0.032 \\
\hline Pre-pregnancy weight $(\mathrm{kg})$ & 0.642 & 0.233 & 0.012 & 0.041 & 0.373 & 0.071 \\
\hline Family history of hypertension (H) & 0.638 & 0.119 & 0.005 & 0.069 & 0.447 & 0.029 \\
\hline Education $<12$ years & 0.629 & 0.05 & 0.018 & 0.034 & 0.376 & 0.034 \\
\hline No folic acid supplementation & 0.625 & 0.032 & 0.005 & 0.010 & 0.373 & 0.028 \\
\hline Prior $\mathrm{GH} / \mathrm{PE}$ & 0.622 & 0.097 & 0.050 & 0.080 & 0.098 & 0.602 \\
\hline Maternal height $(\mathrm{cm})$ & 0.589 & 0.289 & 0.002 & 0.253 & 0.157 & 0.448 \\
\hline Smoking in I trimester & 0.588 & 0.319 & 0.004 & 0.266 & 0.155 & 0.255 \\
\hline GWG (c) & 0.586 & 0.407 & 0.002 & 0.205 & 0.238 & 0.249 \\
\hline Place of residence (c) & 0.586 & 0.187 & 0.001 & 0.161 & 0.174 & 0.302 \\
\hline Treatment of infertility & 0.585 & 0.163 & 0.005 & 0.251 & -0.121 & 0.436 \\
\hline Urogenital infection & 0.568 & 0.188 & 0.0008 & 0.258 & 0.091 & 0.428 \\
\hline GWG $(\mathrm{kg})$ & 0.565 & 0.72 & 0.006 & 0.165 & 0.055 & 0.791 \\
\hline GWG $>15 \mathrm{~kg}$ & 0.563 & 0.507 & 0.0004 & 0.577 & 0.084 & 0.675 \\
\hline No multivitamins supplementation & 0.557 & 0.319 & -0.0001 & 0.870 & 0.05 & 0.803 \\
\hline In vitro fertilization & 0.555 & 0.174 & 0.003 & 0.372 & -0.183 & 0.239 \\
\hline GWG $>10 \mathrm{~kg}$ & 0.555 & 0.49 & 0.0001 & 0.792 & 0.094 & 0.631 \\
\hline Hypothyroidism & 0.553 & 0.655 & 0.005 & 0.124 & 0.252 & 0.157 \\
\hline
\end{tabular}

* A $p$-value < 0.05 was statistically significant. AUC, area under receiver operating characteristic curve; IDI, Integrated Discrimination Improvement; NRI, Net Reclassification Improvement;

(c), categories of independent variables (described in the Methodology); BMI, body mass index; H, hypertension in family history; GWG, gestational weight gain. 
Supplementary Materials Figure S1 shows the strongest NRI and IDI indexes in GH and PE prediction for the models extended with the abovementioned maternal characteristics.

Finally, (see Figure 1) the sum of the sequences obtained from these three measures (AUC, IDI, and NRI) was calculated, resulting in a new order of significance of the maternal factors, highlighting those factors which showed the greatest improvement in prediction in the analyses conducted (ranking first in the sequences). Figure 1A shows that the variables that best improved the GH prediction were pre-pregnancy BMI categories (c), BMI continuous and BMI $\geq 25 \mathrm{~kg} / \mathrm{m}^{2}$, then prior GH/PE, followed by BMI $\geq 30 \mathrm{~kg} / \mathrm{m}^{2}$, then GWG categories (c), the lack of multivitamins supplementation in II-III trimester, a lower financial status, chronic hypertension in the father, (c) and then maternal hypertension (c). The variables that best improved the PE prediction were, in turn, pre-pregnancy BMI categories (c) and BMI $\geq 30 \mathrm{~kg} / \mathrm{m}^{2}$, then chronic hypertension in the mother, then BMI $\geq 25 \mathrm{~kg} / \mathrm{m}^{2}$, followed by chronic hypertension in the father, lower financial status, interpregnancy interval categories (c), and then education $<12$ years.

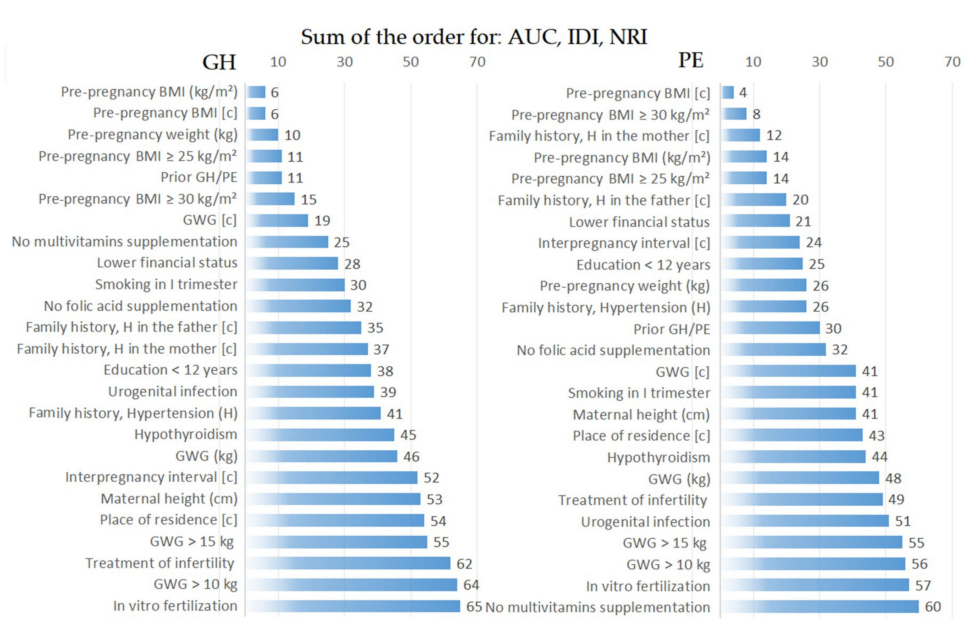

(A)

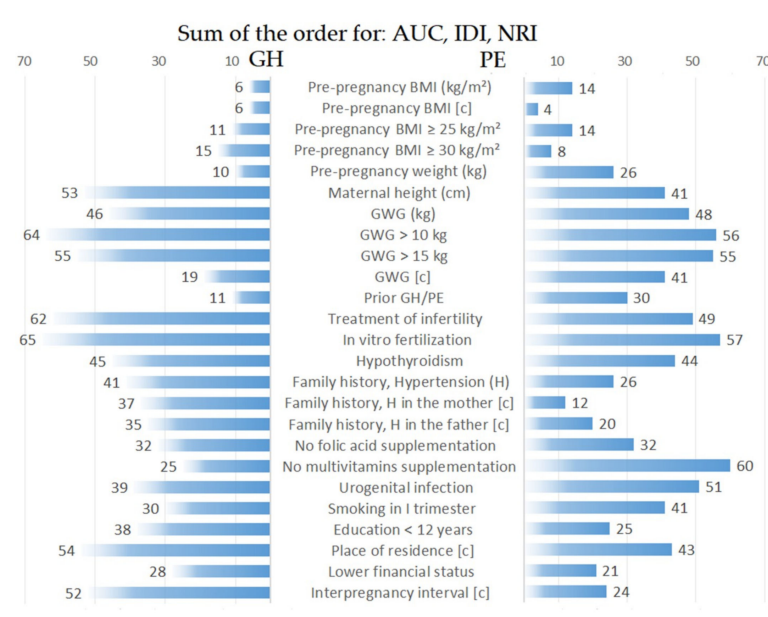

(B)

Figure 1. A new order of significance of the maternal factors after the sum of the sequences obtained from the three measures (AUC, IDI and NRI). The image at the top (A) highlights those maternal traits that improved predicting the most. The image at the bottom (B) shows the variables and their groups and highlights the differences between GH and PE for each variable. BMI, body mass index; (c), categories as described for independent variables in the Methodology; GWG, gestational weight gain; $\mathrm{H}$, hypertension in family history; AUC, area under receiver operating characteristic curve; IDI, Integrated Discrimination Improvement; NRI, Net Reclassification Improvement; GH, gestational hypertension; PE, preeclampsia. 


\section{Discussion}

In this analysis, we assessed a prospectively recruited cohort of women with a single pregnancy. We examined the women who developed isolated gestational hypertension (GH) $(12.4 \%)$ and preeclampsia (PE) $(2.6 \%)$ and those who remained normotensive $(85 \%)$. The aim of our study was to prioritize the importance of maternal factors in predicting GH and PE. The final result included the results of three prediction measures (AUC of the extended model, IDI, and NRI) that can be used to assess the change (improvement) of the prediction. We found that pre-pregnancy BMI (assessed as a categorical and/or continuous and/or dichotomous variable) was more important in the development of GH and PE compared to other clinical factors.

Importantly, we assessed multivariate prediction models to investigate the importance of pre-pregnancy obesity/overweight, and not to confirm that the greater number of predictors increases the prediction. Our analysis has several advantages over the widely used odds ratio calculations or AUC analysis. IDI determines the mean change in disease probability due to the addition of a new potential marker to the model. NRI gives a clinically very favorable interpretation by providing the percentage of people in whom the addition of the marker under study improves or worsens the prediction (classification). By summing up the marker hierarchy obtained in the AUC, IDI, and NRI examination, we established the final predictor hierarchy taking into consideration many mathematical results.

After taking into account all the prediction measures (AUC, IDI, and NRI), the variables that best improved the GH prediction were pre-pregnancy BMI (including BMI $\geq 25 \mathrm{~kg} / \mathrm{m}^{2}$ ), then prior $\mathrm{GH} / \mathrm{PE}$, then $\mathrm{BMI} \geq 30 \mathrm{~kg} / \mathrm{m}^{2}$, GWG categories (c), the lack of multivitamins supplementation in the second/third trimester, and a lower financial status. Chronic hypertension in the father was ranked next, followed by maternal hypertension, while infertility treatment and IVF were the last items in the ranking. The variables that best improved the PE prediction were, in turn, pre-pregnancy BMI (including BMI $\geq 30 \mathrm{~kg} / \mathrm{m}^{2}$ ), then family history and chronic hypertension in the mother, and then $\mathrm{BMI} \geq 25 \mathrm{~kg} / \mathrm{m}^{2}$, chronic hypertension in the father, lower financial status, interpregnancy interval categories (c), and education $<12$ years.

Our results showed the great importance of pre-pregnancy obesity/overweight in predicting GH and PE, as reflected in the literature. Many studies have shown that pre-pregnancy obesity is an independent risk factor for hypertension in pregnancy [7-12]. Our previous analysis showed that obese women had a statistically significant five-fold higher risk of GH and a nine-fold higher risk of PE compared to women with normal BMI, and these results were obtained after adjusting for many confounding variables, including excessive GWG [7].

Importantly, in the current analysis, there were also differences in the results for BMI; we found the relationship between GH and pre-pregnancy BMI $\geq 25 \mathrm{~kg} / \mathrm{m}^{2}$, and the relationship between PE and $\mathrm{BMI} \geq 30 \mathrm{~kg} / \mathrm{m}^{2}$. It indicates a lower pre-pregnancy BMI threshold in the GH development, compared to the PE development, which we also found in our previous study; the threshold BMI for the higher risk of GH was $24.3 \mathrm{~kg} / \mathrm{m}^{2}$ and for the higher risk of PE was $28.2 \mathrm{~kg} / \mathrm{m}^{2}$ (second cutoff point in the graph) [7]. The differences in these results for GH and PE are small, but they may suggest that severe obesity-related disorders are of greater importance in the development of PE. Early PE (onset $<34$ th week) is characterized by a more severe course, more frequent complications in the mother, and complications in the fetus (intrauterine growth restriction (IUGR), as well as fetal hypoxia or death of the fetus), which may suggest a significant contribution of placental circulation pathology. In late $\mathrm{PE}$, the placenta is often normal; therefore, this form of the disease may be characterized by a lower frequency of fetal complications [13,16,27-29]. It was also found that PE manifesting mainly maternal symptoms may display risk factors similar to those of GH (obesity, insulin-resistance, hyperlipidemia, and chronic hypertension), which may suggest the presence of disorders in the mother's blood vessels before pregnancy [13]. Very interesting results were obtained in a large population study by French authors; higher BMI values were associated with late-onset PE, and not with early onset PE. At the same time, in rich countries, $90 \%$ of PE cases have been reported to be of late onset, and low-income 
countries estimate this percentage at 60-70\% [21]. A comparison of the current and older literature shows that, in the middle of the last century, overweight and/or obesity were not mentioned as risk factors for hypertension in pregnancy, but there was no obesity epidemic in those years.

The clinical implications of our result are very direct and clearly related to the need to intensify education in women of childbearing age on the dangers of obesity and overweight, the positive role of adequate physical activity and proper diet. The diet of pregnant women should provide the right amount of nutrients and calories. Nutrition standards in Poland are similar to those recommended by World Health Organization (WHO), Institute of Medicine, and European Food Safety Authority (EFSA) [30]. According to Polish guidelines, four to five meals a day are recommended and an energy consumption in the second and third trimesters increased by 360 and $475 \mathrm{kcal} /$ day, respectively. Fats (mainly polyunsaturated fatty acids) should account for $20-35 \%$ of the energy requirement, and fat consumption in the second and third trimester should increase by 8-14 and 11-18 g (respectively), compared to the value before pregnancy. Carbohydrate intake should provide $45-60 \%$ of calories, but simple sugars should provide no more than $10 \%$. It is recommended that pregnant women consume $1.2 \mathrm{~g}$ of protein per $\mathrm{kg}$ of body weight (about 54-90 g per day), including animal protein in about $60 \%$. In Poland, $300 \mathrm{~g} / 400 \mathrm{~g}$ of fruit/vegetables is the recommended daily amount in the first trimester, and $400 \mathrm{~g} / 500 \mathrm{~g}$ in the second-third trimester. The diet should provide the right amount of macroand micro-nutrients (e.g., vitamins and trace elements) [30]. According to the recommendations of the Institute of Medicine (IOM) of 2009, optimal weight gain depends on the pre-pregnancy BMI, and for underweight, normal weight, overweight, and obesity, it should be 12.5-18, 11.5-16, 7-11.5, and 5-9 kg, respectively [7]. Physical activity is essential in the treatment of obesity. According to WHO, adults should show a minimum of 150 min of moderate activity a week; similar guidelines apply in pregnancy, but with possible contraindications [30].

Our results also showed that gestational weight gain (GWG) was important in predicting GH compared to pre-pregnancy BMI, but GWG may be associated with fluid retention, and this clinical factor had limited predictive value [7,31,32]. In our cohort, the percentage of women with GWG above the IOM recommendation range was $36.8 \%$, but for the women with excessive pre-pregnancy BMI, it was $59.0 \%$.

The mechanisms of the influence of obesity on the higher risk of PE/GH are not fully understood; however, obesity in the mother have been linked to insulin resistance, inflammation (including in the placenta), and restriction of placental blood flow [33]. The increased inflammation and oxidative stress associated with obesity are considered; this may exacerbate the underlying disorders underlying the development of PE [10,34-36].

The etiology of pregnancy-induced hypertension is not fully explained, but the pathogenesis of PE takes into account disturbances in trophoblast invasion into the walls of the spiral arteries, which results in a lack of remodeling, high-resistance circulation, and placental ischemia [37,38]. The balance of many placental biomarkers is disturbed, oxidative stress and inflammation in both the placenta and in the mother's circulation are intensified, and the effect is endothelial function damage and an increase in blood pressure [16,37-39]. There are many studies available in the literature which have found associations between lower levels of antioxidants in pregnant women with PE [40]. At the same time, disorders of the woman's cardiovascular system are taken into account, including factors affecting endothelium (e.g., by increased oxidative stress) [13]. In our previous analyses, we found associations with lower maternal serum selenium (Se) levels (Se being a potent antioxidant) in the first trimester and a higher risk of pregnancy-induced hypertension, including a higher risk of GH [26,34].

In our cohort, the pregnant women had no chronic disease and came from a single region, which matched the study groups in terms of the quality of prenatal care, and ruled out the influence of ethnic/racial differences. The exclusion of high-risk factors (such as multiple pregnancies and inflammatory diseases including preexisting hypertension) resulted in a low number of preeclampsia (PE) cases in our study. We did not separately assess PE phenotypes. Moreover, due to the small number of women with prior PE, we assessed all prior GH/PE cases of hypertension. Adverse neonatal 
outcomes among our GH and PE cases were significantly more frequent than in normotensive women, but were more severe in the women who developed PE (higher frequency of IUGR cases, lower mean birth weight, and lower mean gestational age, including a much higher percentage of preterm births).

Early identification of women at risk of pregnancy-induced hypertension is needed so they can be placed under increased surveillance as early as possible. Although we did not find such an analysis in the literature, our basic results showing higher GH and/or PE odds ratios for all maternal features tested (Tables 1 and 2 and Supplementary Materials Tables S2 and S3) are consistent with the results in the literature [41-43]. The slightly different hierarchies of maternal factors in GH and PE prediction found in our study may suggest different or common mechanisms of their development.

In the current analysis, "prior GH/PE" was the strongest variable in predicting GH and PE in the assessment of IDI indexes (Tables 4 and 5) and in the assessment of odds ratios (OR $=22.9$ and $\mathrm{OR}=27.5$, respectively) (Table 2 and Supplementary Materials Table S3). However, when the three predictive indexes (AUC, IDI, and NRI) were summed up, this variable was placed high (but not the highest) in the GH prediction ranking. The weaker final association of this maternal feature with the PE prediction may be due to the very small number of women with prior preeclampsia (PE). The literature results indicate a relationship of prior PE with a higher risk of PE, especially early onset PE $(<32$ th week and $<34$ th week), but not all of these results are based on multivariate analyses $[8,9,13,44]$.

In this analysis, a family history of chronic hypertension was of relatively high importance in predicting PE and GH. When the three measures (AUC, IDI, and NRI) were summed up, family history of hypertension was of greater importance in predicting PE. Importantly, maternal hypertension predicted PE more strongly than paternal hypertension. These results may reflect the influence of genetic factors reported in the literature $[9,45,46]$.

Lower education and lower financial status were other important PE and GH predictors we found. Associations of lower socioeconomic indicators with a higher risk of hypertension in pregnancy are confirmed in the literature $[47,48]$. Lower socioeconomic indicators may be associated with an unhealthy lifestyle, affecting predictors such as eating unhealthy food, pre-pregnancy obesity, smoking, and lack of adequate prenatal care, including not taking multivitamin supplementation during pregnancy.

In our analysis combining the results of three statistical measures, other risk factors such as longer interpregnancy interval, the lack of multivitamin (and multi-micronutrient) supplementation in the second/third trimester, first trimester smoking, infertility treatment and (separately) in vitro fertilization (IVF), urogenital infection, and hypothyroidism were poorer GH and PE predictors. However, we would like to point out that these factors were associated with higher odds ratios of both forms of the disease and increased the predictive value of the base model (maternal age and primiparity), but less so compared to pre-pregnancy obesity and the factors mentioned above. There are results in the literature confirming the association of these maternal factors with a higher risk of GH and PE $[8,47,49,50]$.

In this analysis, maternal age and primiparity were selected for the primary predictive model and therefore were not assessed separately. Of course, the choice of these two features for the basic predictive model was dictated by the results found in the literature, as both are known risk factors for hypertension in pregnancy $[9,20,51,52]$.

One strength of our study was the prospective cohort study model. An advantage was the exclusion of chronic high-risk factors, which made it possible to assess maternal characteristics as predictors of the disease. Another advantage was being able to confirm the results by using several statistical methods.

The limitation of our study was a small number of preeclampsia cases. We did not assess physical activity or body composition, which would allow additional conclusions to be drawn. The participants self-reported some anthropometric data, but the most important data came from the medical records. 


\section{Conclusions}

In this study, the pre-pregnancy BMI was a strong factor in predicting both forms of pregnancy-induced hypertension, i.e., isolated gestational hypertension (GH) and preeclampsia (PE). Pre-pregnancy obesity and overweight were the most likely ones to increase the probability of developing both GH and PE, as compared to other risk factors. Excessive gestational weight gain (GWG) was also an important predictor, which, together with the role of excessive BMI, highlights the urgent need for educational interventions to adhere to guidelines and optimize diet and exercise in women of childbearing age and pregnant women.

In this study, we also found a subtle but distinct difference in the threshold value of BMI in the development of $\mathrm{GH}$ and PE, suggesting the need for further research on this topic. It seems important to identify associations of obesity or overweight with various phenotypes of hypertension in pregnancy, which may help in determining the mechanisms of this pathology and in determining the treatment strategy.

This study also showed clear differences in the importance of some risk factors in predicting PE and GH. Hierarchies of PE and GH risk factors may suggest different (or common) mechanisms of their development.

Supplementary Materials: The following are available online at http://www.mdpi.com/2072-6643/12/9/2681/s1. Figure S1: IDI and NRI index values after extending the predictive base model with the abovementioned maternal characteristics. Table S1: Basic characteristics of the women with excessive pre-pregnancy BMI. Table S2: Complete characteristics of normotensive women and women developing hypertension in pregnancy. Table S3: Set of odds ratios of pregnancy hypertension forms for many categories of the mother's features. Table S4: Set of AUC values in the extended multivariate models in the assessment of the probability of gestational hypertension $(\mathrm{GH})$ and preeclampsia (PE). Table S5: Set of values of Net Reclassification Improvement (NRI) in the extended multivariate models in the assessment of the probability of gestational hypertension (GH) and preeclampsia (PE). Table S6: Set of values of Integrated Discrimination Improvement (IDI) in the extended multivariate models in the assessment of the probability of gestational hypertension $(\mathrm{GH})$ and preeclampsia (PE).

Author Contributions: Conceptualization, M.L.; methodology, M.L.; software, M.L.; validation, M.L.; formal analysis, M.L.; investigation, M.L. and B.W.; resources, M.L.; data curation, M.L.; writing-original draft preparation, M.L.; writing-review and editing, M.L.; visualization, M.L. and B.W.; supervision, J.L., S.S. and M.L.; project administration, M.L. All authors have read and agreed to the published version of the manuscript.

Funding: This research received no external funding.

Acknowledgments: The authors would like to thank pregnant women at the University Obstetrics and Gynecology Hospital in Poznań, Poland, for their participation in this study.

Conflicts of Interest: The authors declare no conflict of interest.

\section{References}

1. Jaacks, L.M.; Vandevijvere, S.; Pan, A.; McGowan, C.J.; Wallace, C.; Imamura, F.; Mozaffarian, D.; Swinburn, B.; Ezzati, M. The obesity transition: Stages of the global epidemic. Lancet Diabetes Endocrinol. 2019, 7, $231-240$. [CrossRef]

2. Hauspurg, A.; Countouris, M.E.; Jeyabalan, A.; Hubel, C.A.; Roberts, J.M.; Schwarz, E.B.; Catov, J.M. Risk of hypertension and abnormal biomarkers in the first year postpartum associated with hypertensive disorders of pregnancy among overweight and obese women. Pregnancy Hypertens. 2019, 15, 1-6. [CrossRef] [PubMed]

3. Marciniak, A.; Patro-Małysza, J.; Kimber-Trojnar, Ż.; Marciniak, B.; Oleszczuk, J.; Leszczyńska-Gorzelak, B. Fetal programming of the metabolic syndrome. Taiwan J. Obstet. Gynecol. 2017, 56, 133-138. [CrossRef]

4. Staud, F.; Karahoda, R. Trophoblast: The central unit of fetal growth, protection and programming. Int. J. Biochem. Cell Biol. 2018, 105, 35-40. [CrossRef] [PubMed]

5. Fajersztajn, L.; Veras, M.M. Hypoxia: From Placental Development to Fetal Programming. Birth Defects Res. 2017, 109, 1377-1385. [CrossRef]

6. Hanafi, M.Y.; Saleh, M.M.; Saad, M.I.; Abdelkhalek, T.M.; Kamel, M.A. Transgenerational effects of obesity and malnourishment on diabetes risk in F2 generation. Mol. Cell. Biochem. 2016, 412, 269-280. [CrossRef] 
7. Lewandowska, M.; Więckowska, B.; Sajdak, S. Pre-Pregnancy Obesity, Excessive Gestational Weight Gain, and the Risk of Pregnancy-Induced Hypertension and Gestational Diabetes Mellitus. J. Clin. Med. 2020, 9, 1980. [CrossRef]

8. Bartsch, E.; Medcalf, K.E.; Park, A.L.; Ray, J.G. High Risk of Pre-eclampsia Identification Group Clinical risk factors for pre-eclampsia determined in early pregnancy: Systematic review and meta-analysis of large cohort studies. BMJ 2016, 353, i1753. [CrossRef]

9. Phipps, E.A.; Thadhani, R.; Benzing, T.; Karumanchi, S.A. Author Correction: Pre-eclampsia: Pathogenesis, novel diagnostics and therapies. Nat. Rev. Nephrol. 2019, 15, 386. [CrossRef]

10. Olson, K.N.; Redman, L.M.; Sones, J.L. Obesity “complements” preeclampsia. Physiol. Genom. 2019, 51, 73-76. [CrossRef]

11. Young, O.M.; Twedt, R.; Catov, J.M. Pre-pregnancy maternal obesity and the risk of preterm preeclampsia in the American primigravida. Obesity 2016, 24, 1226-1229. [CrossRef] [PubMed]

12. Patro Golab, B.; Santos, S.; Voerman, E.; Lawlor, D.A.; Jaddoe, V.W.V.; Gaillard, R. MOCO Study Group Authors Influence of maternal obesity on the association between common pregnancy complications and risk of childhood obesity: An individual participant data meta-analysis. Lancet Child Adolesc. Health 2018, 2, 812-821. [CrossRef]

13. Poon, L.C.; Shennan, A.; Hyett, J.A.; Kapur, A.; Hadar, E.; Divakar, H.; McAuliffe, F.; da Silva Costa, F.; von Dadelszen, P.; McIntyre, H.D.; et al. The International Federation of Gynecology and Obstetrics (FIGO) initiative on pre-eclampsia: A pragmatic guide for first-trimester screening and prevention. Int. J. Gynaecol. Obstet. 2019, 145, 1-33. [CrossRef]

14. Shen, M.; Smith, G.N.; Rodger, M.; White, R.R.; Walker, M.C.; Wen, S.W. Comparison of risk factors and outcomes of gestational hypertension and pre-eclampsia. PLoS ONE 2017, 12, e0175914. [CrossRef] [PubMed]

15. American College of Obstetricians and Gynecologists' Committee on Practice Bulletins-Obstetrics Gestational Hypertension and Preeclampsia: ACOG Practice Bulletin, Number 222. Obstet. Gynecol. 2020, 135, e237-e260. [CrossRef]

16. Sufriyana, H.; Wu, Y.-W.; Su, E.C.-Y. Prediction of Preeclampsia and Intrauterine Growth Restriction: Development of Machine Learning Models on a Prospective Cohort. JMIR Med. Inf. 2020, 8, e15411. [CrossRef]

17. Hromadnikova, I.; Kotlabova, K.; Hympanova, L.; Krofta, L. Gestational hypertension, preeclampsia and intrauterine growth restriction induce dysregulation of cardiovascular and cerebrovascular disease associated microRNAs in maternal whole peripheral blood. Thromb. Res. 2016, 137, 126-140. [CrossRef]

18. Aryan, L.; Medzikovic, L.; Umar, S.; Eghbali, M. Pregnancy-associated cardiac dysfunction and the regulatory role of microRNAs. Biol. Sex Differ. 2020, 11, 14. [CrossRef]

19. Elharram, M.; Dayan, N.; Kaur, A.; Landry, T.; Pilote, L. Long-Term Cognitive Impairment After Preeclampsia: A Systematic Review and Meta-analysis. Obstet. Gynecol. 2018, 132, 355-364. [CrossRef]

20. Sandström, A.; Snowden, J.M.; Höijer, J.; Bottai, M.; Wikström, A.-K. Clinical risk assessment in early pregnancy for preeclampsia in nulliparous women: A population based cohort study. PLoS ONE 2019, 14, e0225716. [CrossRef]

21. Robillard, P.-Y.; Dekker, G.; Scioscia, M.; Bonsante, F.; Iacobelli, S.; Boukerrou, M.; Hulsey, T.C. Increased BMI has a linear association with late-onset preeclampsia: A population-based study. PLOS ONE 2019, 14, e0223888. [CrossRef] [PubMed]

22. Omani-Samani, R.; Ranjbaran, M.; Amini, P.; Esmailzadeh, A.; Sepidarkish, M.; Almasi-Hashiani, A. Adverse maternal and neonatal outcomes in women with preeclampsia in Iran. J. Matern. Fetal Neonatal Med. 2019, 32, 212-216. [CrossRef] [PubMed]

23. DeLong, E.R.; DeLong, D.M.; Clarke-Pearson, D.L. Comparing the areas under two or more correlated receiver operating characteristic curves: A nonparametric approach. Biometrics 1988, 44, 837-845. [CrossRef] [PubMed]

24. Pencina, M.J.; D'Agostino, R.B.; D'Agostino, R.B.; Vasan, R.S. Evaluating the added predictive ability of a new marker: From area under the ROC curve to reclassification and beyond. Stat. Med. 2008, 27, 157-172; discussion 207-212. [CrossRef]

25. Cook, N.R. Quantifying the added value of new biomarkers: How and how not. Diagn. Progn. Res. 2018, 2, 14. [CrossRef] 
26. Lewandowska, M.; Sajdak, S.; Lubiński, J. Serum Selenium Level in Early Healthy Pregnancy as a Risk Marker of Pregnancy Induced Hypertension. Nutrients 2019, 11, 1028. [CrossRef]

27. Tarca, A.L.; Romero, R.; Benshalom-Tirosh, N.; Than, N.G.; Gudicha, D.W.; Done, B.; Pacora, P.; Chaiworapongsa, T.; Panaitescu, B.; Tirosh, D.; et al. The prediction of early preeclampsia: Results from a longitudinal proteomics study. PLoS ONE 2019, 14, e0217273. [CrossRef]

28. Van Esch, J.J.A.; van Heijst, A.F.; de Haan, A.F.J.; van der Heijden, O.W.H. Early-onset preeclampsia is associated with perinatal mortality and severe neonatal morbidity. J. Matern. Fetal Neonatal Med. 2017, 30, 2789-2794. [CrossRef]

29. Erez, O.; Romero, R.; Maymon, E.; Chaemsaithong, P.; Done, B.; Pacora, P.; Panaitescu, B.; Chaiworapongsa, T.; Hassan, S.S.; Tarca, A.L. The prediction of late-onset preeclampsia: Results from a longitudinal proteomics study. PLoS ONE 2017, 12, e0181468. [CrossRef]

30. Ługowska, K.; Kolanowski, W. The Nutritional Behaviour of Pregnant Women in Poland. Int. J. Environ. Res. Public Health 2019, 16, 4357. [CrossRef]

31. LifeCycle Project-Maternal Obesity and Childhood Outcomes Study Group; Voerman, E.; Santos, S.; Inskip, H.; Amiano, P.; Barros, H.; Charles, M.-A.; Chatzi, L.; Chrousos, G.P.; Corpeleijn, E.; et al. Association of Gestational Weight Gain With Adverse Maternal and Infant Outcomes. JAMA 2019, 321, 1702-1715. [CrossRef] [PubMed]

32. Hillesund, E.R.; Seland, S.; Bere, E.; Sagedal, L.R.; Torstveit, M.K.; Lohne-Seiler, H.; Vistad, I.; Øverby, N.C. Preeclampsia and gestational weight gain in the Norwegian Fit for Delivery trial. BMC Res. Notes 2018, 11, 282. [CrossRef] [PubMed]

33. Cheung, C.Y.; Roberts, V.H.J.; Frias, A.E.; Brace, R.A. Effects of maternal western-style diet on amniotic fluid volume and amnion VEGF profiles in a nonhuman primate model. Physiol. Rep. 2018, 6, e13894. [CrossRef] [PubMed]

34. Lewandowska, M.; Więckowska, B.; Sajdak, S.; Lubiński, J. First Trimester Microelements and their Relationships with Pregnancy Outcomes and Complications. Nutrients 2020, 12, 1108. [CrossRef] [PubMed]

35. Izaola, O.; de Luis, D.; Sajoux, I.; Domingo, J.C.; Vidal, M. Inflammation and obesity (lipoinflammation). Nutr. Hosp. 2015, 31, 2352-2358. [CrossRef]

36. Saltiel, A.R.; Olefsky, J.M. Inflammatory mechanisms linking obesity and metabolic disease. J. Clin. Investig. 2017, 127, 1-4. [CrossRef]

37. Staff, A.C. The two-stage placental model of preeclampsia: An update. J. Reprod. Immunol. 2019, 134-135, 1-10. [CrossRef]

38. Rozas-Villanueva, M.F.; Casanello, P.; Retamal, M.A. Role of ROS/RNS in Preeclampsia: Are Connexins the Missing Piece? Int. J. Mol. Sci. 2020, 21, 4698. [CrossRef]

39. Ahmad, I.M.; Zimmerman, M.C.; Moore, T.A. Oxidative stress in early pregnancy and the risk of preeclampsia. Pregnancy Hypertens. 2019, 18, 99-102. [CrossRef]

40. Haram, K.; Mortensen, J.H.; Myking, O.; Magann, E.F.; Morrison, J.C. The Role of Oxidative Stress, Adhesion Molecules and Antioxidants in Preeclampsia. Curr. Hypertens. Rev. 2019, 15, 105-112. [CrossRef]

41. Wright, D.; Tan, M.Y.; O'Gorman, N.; Poon, L.C.; Syngelaki, A.; Wright, A.; Nicolaides, K.H. Predictive performance of the competing risk model in screening for preeclampsia. Am. J. Obstet. Gynecol. 2019, 220, 199. [CrossRef] [PubMed]

42. Antwi, E.; Amoakoh-Coleman, M.; Vieira, D.L.; Madhavaram, S.; Koram, K.A.; Grobbee, D.E.; Agyepong, I.A.; Klipstein-Grobusch, K. Systematic review of prediction models for gestational hypertension and preeclampsia. PLoS ONE 2020, 15, e0230955. [CrossRef] [PubMed]

43. Antwi, E.; Klipstein-Grobusch, K.; Browne, J.L.; Schielen, P.C.; Koram, K.A.; Agyepong, I.A.; Grobbee, D.E. Improved prediction of gestational hypertension by inclusion of placental growth factor and pregnancy associated plasma protein-a in a sample of Ghanaian women. Reprod. Health 2018, 15, 56. [CrossRef]

44. Founds, S.A.; Tsigas, E.; Ren, D.; Barmada, M.M. Associating Symptom Phenotype and Genotype in Preeclampsia. Biol. Res. Nurs. 2018, 20, 126-136. [CrossRef] [PubMed]

45. Ananth, C.V.; Jablonski, K.; Myatt, L.; Roberts, J.M.; Tita, A.T.N.; Leveno, K.J.; Reddy, U.M.; Varner, M.W.; Thorp, J.M.; Mercer, B.M.; et al. Risk of Ischemic Placental Disease in Relation to Family History of Preeclampsia. Am. J. Perinatol. 2019, 36, 624-631. [CrossRef] [PubMed] 
46. Serrano, N.C.; Quintero-Lesmes, D.C.; Dudbridge, F.; Leon, L.J.; Hingorani, A.D.; Williams, D.J.; Casas, J.P. Family history of pre-eclampsia and cardiovascular disease as risk factors for pre-eclampsia: The GenPE case-control study. Hypertens. Pregnancy 2020, 39, 56-63. [CrossRef]

47. Umesawa, M.; Kobashi, G. Epidemiology of hypertensive disorders in pregnancy: Prevalence, risk factors, predictors and prognosis. Hypertens. Res. 2017, 40, 213-220. [CrossRef]

48. Ross, K.M.; Dunkel Schetter, C.; McLemore, M.R.; Chambers, B.D.; Paynter, R.A.; Baer, R.; Feuer, S.K.; Flowers, E.; Karasek, D.; Pantell, M.; et al. Socioeconomic Status, Preeclampsia Risk and Gestational Length in Black and White Women. J. Racial Ethn. Health Dispar. 2019, 6, 1182-1191. [CrossRef]

49. Howe, L.; Hammer, E.; Badger, G.; Bernstein, I.M. Effect of Pregnancy Interval on Second Pregnancy Blood Pressure Following Prior Preeclampsia. Reprod. Sci. 2018, 25, 727-732. [CrossRef]

50. Sohlberg, S.; Stephansson, O.; Cnattingius, S.; Wikström, A.-K. Maternal body mass index, height, and risks of preeclampsia. Am. J. Hypertens. 2012, 25, 120-125. [CrossRef]

51. Phipps, E.; Prasanna, D.; Brima, W.; Jim, B. Preeclampsia: Updates in Pathogenesis, Definitions, and Guidelines. Clin. J. Am. Soc. Nephrol. 2016, 11, 1102-1113. [CrossRef] [PubMed]

52. Khalil, A.; Syngelaki, A.; Maiz, N.; Zinevich, Y.; Nicolaides, K.H. Maternal age and adverse pregnancy outcome: A cohort study. Ultrasound Obstet. Gynecol. 2013, 42, 634-643. [CrossRef] [PubMed]

(C) 2020 by the authors. Licensee MDPI, Basel, Switzerland. This article is an open access article distributed under the terms and conditions of the Creative Commons Attribution (CC BY) license (http://creativecommons.org/licenses/by/4.0/). 